\title{
Analisis Faktor-Faktor Preferensi Etnis Tionghoa Terhadap Bank Syariah di Indonesia
}

\section{Analysis of Factors of Chinese Ethnic Preferences in Islamic Bank Indonesia}

\author{
Yurita Sari ${ }^{1}$, Ujang Sumarwan ${ }^{2}$ M. Nadratuzzaman Hosen ${ }^{3}$ \\ ${ }^{1}$ Mahasiswa Program Studi Manajemen dan Bisnis IPB, Email yuritasari@gmail.com \\ ${ }^{2}$ Prof. Program Studi Manajemen dan Bisnis IPB, Email sumarwan@mb.ipb.ac.id \\ ${ }^{3}$ Dosen Program Studi Manajemen dan Bisnis IPB, Email mnhosen@yahoo.com
}

\begin{abstract}
The research aimed to develop and to test the consistency of the relationship between preference factrs of Chinese Ethnic towards Islamic Banks in Indonesia. According to previous research, customer's internal and external factors as well as marketing strategy of the Islamic Banks are the main reason behind their decisions to become Islamic Banks' customers. However, some of the previous researches have also shown inconsistent result in which it is stated that the religious factor is the main reason for Chinese Ethnic to choose Islamic Banks, whereas some other research concluded that religion has nothing to do with the decision to become customer in Islamic Banks.

In line with the purpose of the research is to analyze how far the factors mentioned above could influence the preference of people with Chinese Ethnicity towards Islamic Banks. The approach used in this research is survey method. Sumarwan (2011) explains that survey is a design of a research which collects data from some respondents that are selected from a population. The sample of this research is Indonesian Chinese Ethnics, including the Muslim ones and also include those who are already a customer in Islamic Banks as well as those who are not. This study specifically analyzes perception attribute variable such as location, higher return, quality service, Islamic bank's reputation and image, product features, marketing, and teknology; and also environment variable, personal variable, culture variable, and lastly preference variable of the Chinese ethnics towards Islamic Banks in Indonesia by using AIDA (awareness, interest, desire) model approach. The data is analyzed by using SEM (structural equation model) technique.
\end{abstract}

An interesting phenomenon of the research is that Islamic Banks use Islamic principles which prohibited the act of Riba', while the Chinese Ethnic customers and the prospective customers also considering the same thing. Most of Chinese Ethnics are Buddhist, Christian, and Catholic which prohibited interests in banking system.

The result of this study concluded that the level of knowledge of Chinese Ethnics that are not yet a customer towards Islamic Banks is lower than the knowledge level of Muslim Chinese Ethnics who are already a customer in Islamic Banks. With AIDA model, it is found that environment variable which consists of social and culture has significant influence towards atribute perception and also towards other AIDA variables such as Awareness, interest and desire.

Keywords : AIDA, Ethnicity, Banking, Shariah, Variable

Abstrak. Penelitian ini bertujuan untuk mengembangkan dan menguji konsistensi hubungan faktor-faktor preferensi Etnis Tionghoa terhadap Bank Syariah di Indonesia. Menurut teori dan review penelitian sebelumnya, faktor internal dan eksternal pelanggan serta strategi pemasaran Bank Syariah dianggap atau dirasakan oleh pelanggan bahwa faktor tersebut akan mempengaruhi keputusan mereka untuk menjadi nasabah Bank Syariah. Namun, beberapa penelitian sebelumnya pula telah menunjukkan hasil yang tidak konsisten di mana beberapa menyatakan bahwa faktor agama menjadi alasan utama untuk berurusan dengan Bank Syariah, padahal yang lain menyatakan bahwa agama tidak berpengaruh terhadap keputusan untuk menjadi nasabah di Bank Syariah.

Sesuai dengan tujuan dari penelitian ini yaitu untuk mengetahui dan menganalisis sampai sejauh mana faktor-faktor yang berpengaruh dalam pembentukan minat Etnis Tionghoa terhadap Bank Syariah. Pendekatan yang dilakukan dalam penelitian ini adalah dengan pendekatan survei. Sumarwan (2011) menjelaskan bahwa survei adalah suatu desain penelitian yang mengumpulkan data dari sejumlah sampel responden yang dipilih dari sebuah populasi. Adapun sampel dalam penelitian ini adalah etnis Tionghoa 
Non Muslim baik yang telah menjadi nasabah Bank Syariah maupun yang belum. Studi ini secara khusus menganalisis variabel persepsi atribut (location, higher return, quality service, Islamic bank's reputation and image, product features, marketing, teknologi), variabel environment, variabel personal, variabel culture, dan variabel preferensi Etnis Tionghoa terhadap Bank Syariah di Indonesia dengan pendekatan model AIDA (awareness, interest, desire). Data di analisis menggunakan teknik analisis structural equation model (SEM).

Fenomena menarik dari penelitian ini adalah Bank Syariah yang menggunakan prinsip Islam dan mengendepankan faktor riba sebagai sesuatu yang dihindari, ternyata Nasabah dan calon nasabah Bank Syariah dari etnis Tionghoa non muslim juga mempertimbangkan faktor riba ini. Etnis Tionghoa Non Muslim beragama Budha, Kristen, Katholik yang ternyata juga mengenal konsep larangan bunga di kalangan agama non muslim .

Hasil penelitian ini yang menyatakan bahwa tingkat pengetahuan etnis Tionghoa non nasabah ternyata memiliki tingkat pengetahuan dan persepsi yang lebih rendah terhadap Bank Syariah dibandingkan dengan tingkat pengetahuan dan persepsi dari nasabah etnis Tionghoa non muslim. Dengan konsep AIDA menemukan bahwa variabel lingkungan yang terdiri dari individu, sosial dan kultur berpengaruh signifikan terhadap persepsi atribut dan berpengaruh terhadap variabel-variabel AIDA yang terdiri dari Awareness, interest dan desire.

Kata Kunci: AIDA, Etnis, Perbankan, Syariah, Variabel

\section{Pendahuluan}

\subsection{Latar Belakang}

Perkembangan industri perbankan dan jasa keuangan telah mengalami kemajuan yang pesat sebagai akibat dari kemajuan teknologi dan kebijaksanaan deregulasi. Adanya deregulasi finansial mengakibatkan fenomena baru yang mengakibatkan iklim persaingan semakin hangat, termasuk didalamnya adalah persaingan dalam perbankan syariah. Hal ini karena persaingan dalam dunia perbankan dipicu oleh pertumbuhan setiap bank. Sedangkan pertumbuhan setiap bank sangat dipengaruhi oleh perkembangan kemampuannya menghimpun dan menyalurkan dana masyarakat, baik berskala kecil maupun besar. Berdasarkan data empiris selama ini, dana yang berasal dari pemilik bank itu sendiri, ditambah cadangan modal yang berasal dari akumulasi keuntungan yang ditanam kembali pada bank, berkisar sebesar 7\% sampai 9\% dari total aktiva bank. Bahkan di Indonesia rata-rata jumlah modal dan cadangan yang dimiliki oleh bank rata-rata $4 \%$ dari total aktiva. Ini berarti bahwa sebagian besar modal kerja bank berasal dari masyarakat, lembaga keuangan lain dan pinjaman likuiditas dari Bank Sentral.

Berdasarkan informasi yang dikeluarkan oleh statistik perbankan syariah maret 2013 selama periode maret 2012 sampai dengan maret 2013 asset, dana pihak ketiga dan pembiayaan perbankan syariah meningkat rata-rata $30 \%$ dibandingkan tahun sebelumnya. Pesatnya pertumbuhan Aset, DPK, PYD beberapa tahun terakhir memberikan indikasi adanya respon positif dari masyarakat terhadap perbankan syariah. Sejalan dengan perkembangan dunia perbankan syariah di ikuti pula dengan maraknya perkembangan kajian akademis dan juga berbagai publikasi berkenaan dengan strategi sukses mengelola Bank Syariah dengan memfokuskan pada orientasi customer muslim sebagai sasaran utamanya. Maka apakah Bank Syariah memang tidak sesuai untuk nasabah non muslim?

Penelitian ini bertujuan untuk mengembangkan dan menguji konsistensi hubungan faktor-faktor preferensi Etnis Tionghoa terhadap Bank Syariah di Indonesia. Menurut teori dan review penelitian sebelumnya, faktor internal dan eksternal pelanggan serta strategi pemasaran Bank Syariah dianggap atau dirasakan oleh pelanggan bahwa faktor tersebut akan mempengaruhi keputusan mereka untuk menjadi nasabah Bank Syariah. Namun, beberapa penelitian 
sebelumnya pula telah menunjukkan hasil yang tidak konsisten di mana beberapa menyatakan bahwa faktor agama menjadi alasan utama untuk berurusan dengan Bank Syariah, padahal yang lain menyatakan bahwa agama tidak berpengaruh terhadap keputusan untuk menjadi nasabah di Bank Syariah. Studi ini secara khusus menganalisis variabel persepsi atribut (location, higher return, quality service, Islamic bank's reputation and image, product features, marketing / business advisor, teknologi), variabel environment, variabel personal, variabel culture, dan variabel preferensi Etnis Tionghoa terhadap Bank Syariah di Indonesia dengan pendekatan model AIDA (awareness, interest, desire).

\subsection{Rumusan Masalah}

Penelitian ini meneliti dan menganalisis faktor - faktor preferensi Etnis Tionghoa terhadap Bank Syariah serta mencoba merumuskan strategi pemasaran produk Bank Syariah dalam rangka pengembangan orientasi pasar non muslim khususnya Etnis Tionghoa di Indonesia. Adapun pokok permasalahan yang diajukan di dalam penelitian ini adalah sebagai berikut:

1. Faktor-faktor apa saja yang mempengaruhi preferensi Etnis Tionghoa terhadap Bank Syariah?

2. Seberapa besar pengaruh faktor-faktor tersebut terhadap keputusan Etnis Tionghoa dalam menentukan minat terhadap Bank Syariah?

3. Bagaimana implikasi yang tepat untuk meningkatkan minat calon nasabah Etnis Tionghoa terhadap Bank Syariah?

\subsection{Tujuan Penelitian}

Dari pertanyaan dan rumusan masalah di atas, dapat ditentukan tujuan dari penelitian sebagai berikut:

1. Menganalisis faktor-faktor apa saja yang mempengaruhi preferensi Etnis Tionghoa terhadap Bank Syariah?

2. Merumuskan strategi dalam upaya meningkatkan minat calon nasabah Etnis Tionghoa terhadap Bank Syariah?

\subsection{Manfaat Penelitian}

Kegunaan penelitian ini ditujukan untuk :

1. Peneliti, Penelitian ini akan berguna untuk melatih diri dalam menganalisa suatu permasalahan secara ilmiah dan sistematis dalam bentuk penulisan tesis.

2. Bagi Akademik atau Peneliti lain, dapat digunakan sebagai sumber referensi dan informasi dan dapat juga digunakan sebagai salah satu landasan bagi peneliti lain yang akan meneliti lebih lanjut mengenai strategi pemasaran produk Bank Syariah dalam rangka pengembangan orientasi pasar non muslim khususnya Etnis Tionghoa di Indonesia.

3. Bagi lembaga keuangan syariah, perbankan syariah, praktisi dan entitas lain dalam penelitian ini dilakukan:

Hasil penelitian ini diharapkan dapat digunakan sebagai pemikiran bagi entitas lembaga keuangan syariah, perbankan syariah, akademisi, para praktisi serta pihak lain nya dalam memahami permasalahan apa yang terjadi dalam proses pemasaran produk Bank Syariah kepada pasar non muslim khususnya Etnis Tionghoa di Indonesia. 


\section{Tinjauan Pustaka}

\subsection{Globalisasi Pemasaran Bisnis dan Agama Dalam Islam}

Globalisasidalam berbisnis atau muamalah, selain tidak dibatasi oleh waktu, juga tidak dibatasi antara muslim dan non muslim. Firman Allah Q.S Al-Mumtahanah: 8-9 :

"Allah tiada melarang kamu untuk berbuat baik dan berlaku adil terhadap orang-orang yang tiada memerangimu karena agama dan tidak (pula) mengusir kamu dari negeri kamu. Sesungguhnya Allah hanya melarang kamu menjadikan sebagai kawanmu orang-orang yang memerangi kamu karena agama dan mengusir kamu dari negerimu dan membantu (orang lain) untuk mengusirmu. Dan barang siapa menjadikan mereka sebagai kawan, maka mereka itulah orang-orang yang zalim."

Kerangka pemasaran dalam bisnis Islami dapat digambarkan sebagai berikut:

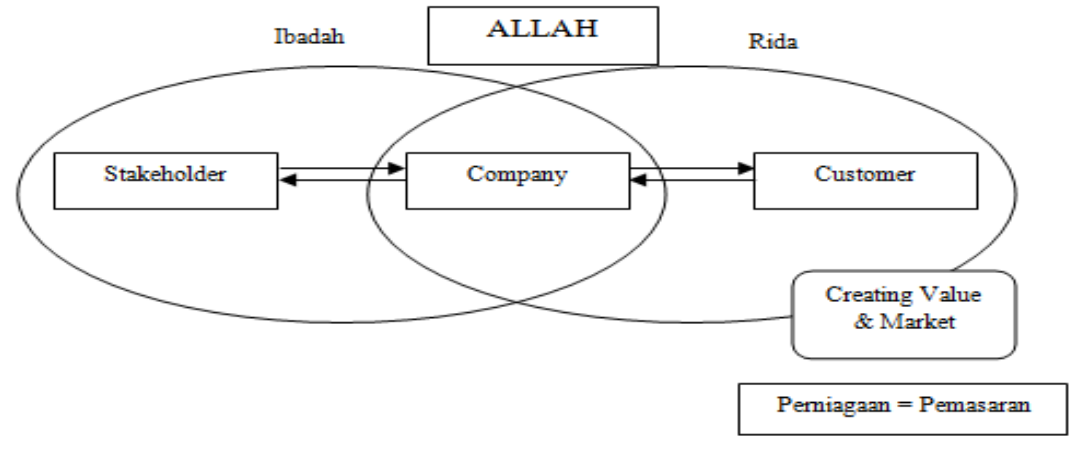

\section{Gambar 1 Kerangka Pemasaran dalam Bisnis Islami}

Sumber : Daromi (2003 : 1)

\subsection{Definisi dan Konsep Pemasaran}

Istilah pemasaran muncul pertama kali sejak kemunculan istilah barter. Proses pemasaran dimulai sebelum barang-barang diproduksi dan tidak berakhir dengan penjualan. Menurut Kotler, marketing (pemasaran) adalah suatu proses sosial dan manajerial yang di dalamnya individu dan kelompok mendapatkan apa yang mereka butuhkan dan inginkan melalui penciptaan, penawaran, dan pertukaran (exchange). Dari definisi Kotler, dapat disimpulkan bahwa "konsep inti pemasaran" adalah sebagai berikut :

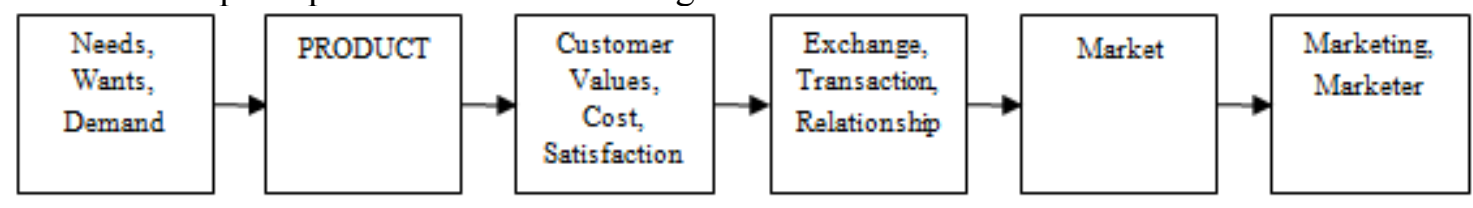

\section{Gambar 2 Konsep Inti Pemasaran}

Sumber: Sutanto, Umam (2013)

Konsep pemasaran bersandar pada empat pilar yaitu pasar sasaran, kebutuhan pelanggan, pemasaran terpadu, dan profitabilitas. Konsep pemasaran menganut pandangan dari luar ke dalam, yaitu memulai dengan pasar yang didefinisikan dengan baik, memusatkan perhatian pada kebutuhan pelanggan, memadukan semua kegiatan yang akan mempengaruhi pelanggan dan menghasilkan laba melalui pemuasan pelanggan. 


\subsection{Strategi Pemasaran}

Strategi pemasaran adalah serangkaian tujuan dan sasaran, kebijakan serrta aturan yang memberi arah kepada usaha-usaha pemasaran dari waktu ke waktu pada masing-masing tingkatan serta lokasinya. Strategi pemasaran modern secara umum terdiri dari tiga tahap yaitu: segmentasi pasar (segmenting), penetapan pasar sasaran (targeting), dan penetapan posisi pasar (positioning) (Kotler, 2010). Setelah mengetahui segmen pasar, target pasar, dan posisi pasar maka dapat disusun strategi bauran pemasaran (marketing mix) yang terdiri dari strategi produk, harga, penyaluran atau distribusi dan promosi (Assauri, 1998). Menurut McDonald (1995) dalam Ayu (2007), strategi pemasaran adalah tindakan yang terintegrasi dalam upaya memberikan nilai kepada pelanggan dan keunggulan bersaing bagi perusahaan, setiap perusahaan akan berpatokan pada strategi yang telah ditetapkan dalam menjalankan usahanya. Strategi pemasaran yang baik akan memiliki ciri-ciri berikut:

1. Memiliki definisi pasar yang jelas.

2. Merupakan kekuatan yang baik antara kekuatan perusahaan dan kebutuhan pasar.

3. Memiliki kinerja yang relatif lebih baik dibandingkan pesaing-pesaingnya yang menjadi faktor kunci keberhasilan usaha.

\subsection{Perbankan Syariah}

Pengembangan sistem perbankan syariah di Indonesia dilakukan dalam kerangka dual-banking system atau sistem perbankan ganda dalam kerangka Arsitektur Perbankan Indonesia (API), untuk menghadirkan alternatif jasa perbankan yang semakin lengkap kepada masyarakat Indonesia. Secara bersama-sama, sistem perbankan syariah dan perbankan konvensional secara sinergis mendukung mobilisasi dana masyarakat secara lebih luas untuk meningkatkan kemampuan pembiayaan bagi sektor-sektor perekonomian nasional.

Berlakunya Undang-Undang No.21 Tahun 2008 tentang Perbankan Syariah yang terbit tanggal 16 Juli 2008, maka pengembangan industri perbankan syariah nasional semakin memiliki landasan hukum yang memadai dan akan mendorong pertumbuhannya secara lebih cepat lagi. Dengan progres perkembangannya yang impresif, yang mencapai rata-rata pertumbuhan aset lebih dari $65 \%$ pertahun dalam lima tahun terakhir, maka diharapkan peran industri perbankan syariah dalam mendukung perekonomian nasional akan semakin signifikan.

\subsection{Pangsa Pasar}

Menurut Sumarwan et al. (2011) market share atau pangsa pasar adalah persentase pasar yang ditentukan dalam ukuran unit maupun revenuedan dihitung berdasarkan spesific entry. Market share adalah sebuah indikator tentang apa yang dilakukan oleh sebuah perusahaan terhadap kompetitornya dengan dukungan perubahan-perubahan dalam sales. pemahaman tentang pangsa pasar dapat membantu manajer melakukan evaluasi terhadap permintaan utama (primer demand) maupun seleksi pasar. Hal ini berarti pemahaman terhadap pangsa pasar ini juga memungkinkan para manajer untuk mengevaluasi tidak hanya market growth (pertumbuhan pasar) total atau penurunannya tapi juga trend dalam seleksi konsumen di antarakompetitornya. Vranesevic et al. (2002) menjelaskan bahwa pangsa pasar yang tinggi tercipta setelah tercapainya kepuasan pelanggan, hal ini bisa dicapai melalui kultur perusahaan yang baik dalam memproduksi suatu produk.

\subsection{Tionghoa di Indonesia}

Sudah menjadi pendapat umum bahwa golongan minoritas Cina memegang peranan yang amat menentukan dalam kehidupan perekonomian masyarakat Indonesia, sehingga apabila diadakan pembedaan golongan ekonomi lemah dan golongan ekonomi kuat, maka yang kuat selalu diartikan golongan Cina atau non pribumi (Husodo, 1985:65). Pendapat tersebut bisa saja benar 
tergantung dari sudut mana melihatnya dan sektor mana yang menjadi titik perhatiannya. Kenyataannya dalam kehidupan sehari-hari kita sering melihat bahwa etnis Cina memegang peranan penting dalam kegiatan perekonomian masyarakat khususnya yang menyangkut pemenuhan kebutuhan pokok dan biasanya mendominasi kegiatan perekonomian tersebut.

\subsection{Faktor-faktor yang mempengaruhi pengambilan keputusan}

Menurut Engel et al. (1994), bervariasinya proses keputusan konsumen ditentukan oleh faktor pengaruh lingkungan, perbedaan individu, serta proses psikologis. Model prilaku konsumen secara lengkap dapat dilihat pada Gambar 3 berikut:

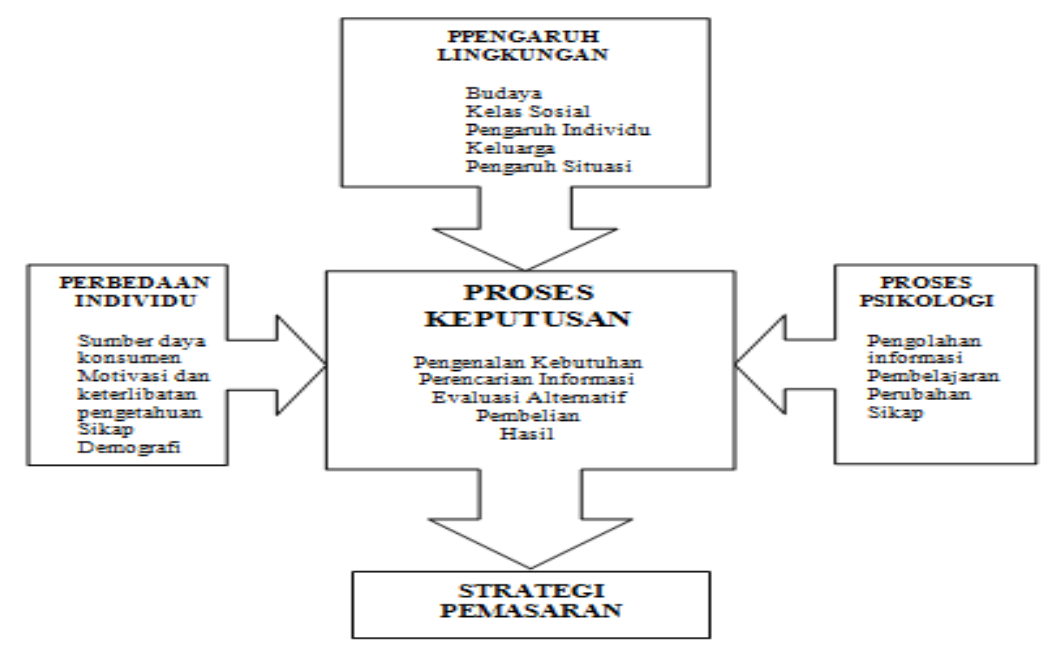

Gambar 3 Model perilaku pengambilan keputusan konsumen dan faktor-faktor yang mempengaruhinya

Sumber : Sumarwan (2011)

\subsection{Model AIDA (Awareness, Interest, Desire, dan Action)}

Model AIDA (Awareness, Interest, Desire, dan Action) mengasumsikan bahwa pembelian melewati tahapan kognitif, pengaruh, dan perilaku secara berturut-turut. Urutan mempelajarimerasakan-melakukan dikatakan sebagai urutan yang dianggap tepat apabila pendengar tersebut memiliki keterlibatan yang tinggi. Urutan alternatif mempelajari-merasakan-melakukan akan relevan jika pendengar tersebut memiliki keterlibatan yang tinggi tetapi memahami hanya sedikit atau tidak ada perbedaan kategori produk. Urutan ketiga mempelajari-merasakanmelakukan akan relevan apabila pendengar tersebut memiliki keterlibatan yang rendah dan memahami sangat sedikit perbedaan dalam kategori produk tersebut. Model AIDA dikembangkan sejak 1920-an dan merupakan model yang berdasarkan tahapan tanggapan konsumen. Model AIDA model meliputi :

a. A-Awareness: mendapatkan atensi dari konsumen, yaitu menyadari keberadaan dari produk

b. I-Interest: meningkatkan ketertarikan konsumen pada produk dengan menyampaikan fitur-fitur, dan manfaat penggunaan produk.

c. D-Desire: meyakinkan konsumen bahwa mereka menginginkan dan berminat terhadap produk tersebut untuk memenuhi kebutuhannya.

d. A-Action: tindakan pembelian atau aksi oleh konsumen. 


\subsection{Kajian Penelitian Terdahulu}

Berdasarkan catatan penulis kajian akademis dan juga berbagai publikasi berkenaan dengan analisis faktor-faktor preferensi Etnis Tionghoa terhadap Bank Syariah Indonesia belum terlalu banyak. Penelitian, kajian akademis dan juga berbagai publikasi berkenaan dengan kajian marketing, consumen behaviour lebih banyak memfokuskan pada orientasi customer muslim sebagai sasaran utamanya, aspek akad dan transaksinya.

\subsection{Kerangka Pemikiran}

Adapun kerangka pemikiran yang akan digunakan di dalam penelitian ini adalah sebagai berikut:

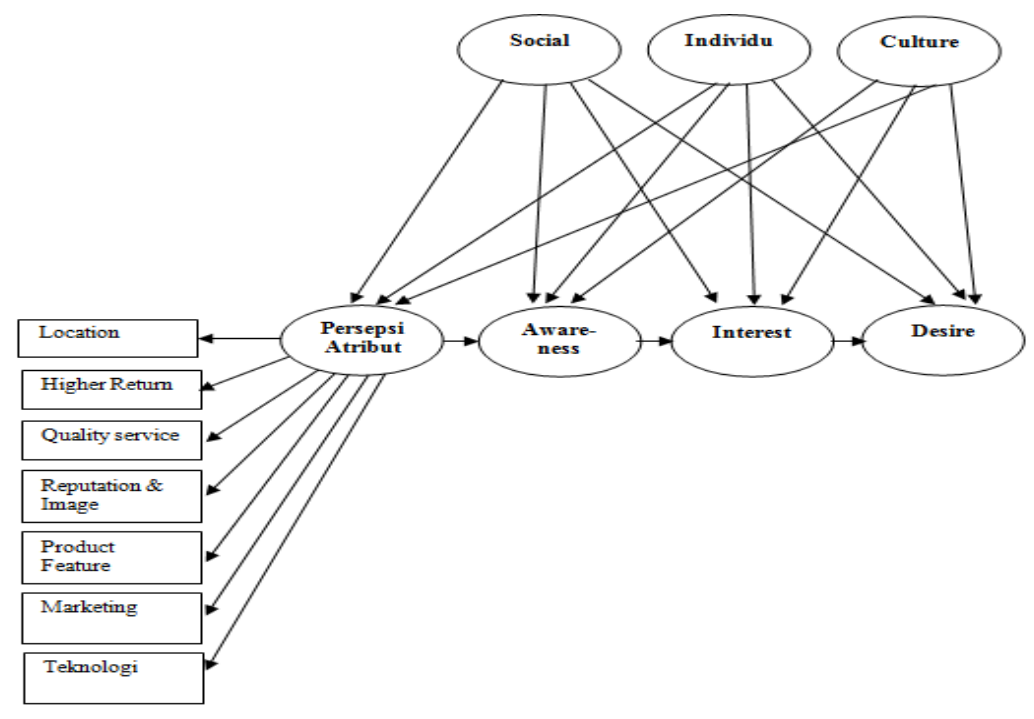

Gambar 5 Kerangka Pemikiran

Hipotesis :

1. Faktor sosial, personal, dan kultur berpengaruh terhadap persepsi atribut etnis Tionghoa terhadap Bank Syariah.

2. Faktor sosial, personal, kultur dan persepsi atribut etnis Tionghoa berpengaruh terhadap awareness Bank Syariah

3. Faktor sosial, personal, kultur, persepsi dan awareness berpengaruh terhadap interest pada Bank Syariah

4. Faktor sosial, personal, kultur, persepsi dan interest berpengaruh terhadap desire pada Bank Syariah.

\section{Metode Penelitian}

Penelitian ini dilaksanakan pada bulan Desember 2014 - Januari 2015. Penelitian dilakukan pada Etnis Tionghoa non muslim di Jabodetabek, baik yang telah memiliki rekening di Bank Syariah maupun yang belum memiliki rekening. Hasil pengumpulan data menunjukkan bahwa dari 160 kuesioner yang disebar sebanyak 10 kuesioner tidak kembali dan 150 kuesioner yang kembali. Dari 150 kuesioner yang kembali terdapat 4 data yang tidak diisi secara lengkap (rusak), sehingga total kuesioner yang dapat diolah sebanyak 146 dengan rincian 73 nasabah Bank Syariah dan 73 bukan nasabah Bank Syariah. Penelitian ini menggunakan data primer yang diperoleh melalui survei dengan teknik pengisian kuesioner kombinasi antara wawancara 
tatap muka (face to face interview) dan pengisian kuesioner yang dilakukan sendiri (personally administered questionnaire).

\subsection{Variabel Penelitian}

Variabel penelitian dapat dilihat pada Tabel 1.

Tabel 1 Variabel Penelitian

\begin{tabular}{cllc}
\hline No & \multicolumn{1}{c}{ Variabel } & \multicolumn{1}{c}{ Sumber Kajian } & Skala \\
\hline 1 & Location & $\begin{array}{l}\text { Erol dan El-Bdour (2007), Khan } \text { et al. (2007), studi } \\
\text { literatur }\end{array}$ & Likert \\
\hline 2 & Higher Return & $\begin{array}{l}\text { Erol dan El-Bdour (2007), Khan } \text { et al. (2007), Awan } \\
\text { dan Bukhari (2011), studi literatur }\end{array}$ & Likert \\
\hline 3 & Quality Service & $\begin{array}{l}\text { Awan dan Bukhari (2011), Erol dan El-Bdour (2007), } \\
\text { studi literatur }\end{array}$ & Likert \\
\hline 4 & $\begin{array}{l}\text { Islamic Bank's } \\
\text { Reputation and }\end{array}$ & $\begin{array}{l}\text { Erol dan El-Bdour (2007), Khan } \text { et al. (2007), studi } \\
\text { literatur }\end{array}$ & Likert \\
\hline 5 & Product Features & Awan dan Bukhari (2011), studi literatur & Likert \\
\hline 6 & $\begin{array}{l}\text { Marketing/Business } \\
\text { Advisor }\end{array}$ & $\begin{array}{l}\text { Awan dan Bukhari (2011), Erol dan El-Bdour (2007), } \\
\text { studi literatur }\end{array}$ & Likert \\
\hline 7 & Personal & Andi (2014), Pasrizal et al. (2012), studi literatur & Likert \\
\hline 8 & Social & Andi (2014), Pasrizal et al. (2012), studi literatur & Likert \\
\hline 9 & Culture & Andi (2014), Pasrizal et al. (2012), studi literatur & Likert \\
\hline 10 & Awareness & Andi (2014), Rahmani et al. (2014), studi literatur & Likert \\
\hline 11 & Interest & Andi (2014), Rahmani et al. (2014), studi literatur & Likert \\
\hline 12 & Teknologi & Studi literatur & Likert \\
\hline & & &
\end{tabular}

\subsection{Analisis Data}

Terdapat tiga proses analisis data yang dilakukan di dalam penelitian ini yaitu pertama, praanalisis data meliputi proses pemeriksaaan data (checking), pembersihan data (cleansing), uji reliabilitas dan validitas kuesioner. Kedua, statistik deskriptif bertujuan untuk mepaparkan berdasarkan frekuensi dan persentase untuk melihat profil responden. Dengan diketahuinya profil responden, maka akan sangat membantu dalam memahami analisis data pada tahap selanjutnya. Ketiga, statistik inferensia, merupakan proses pemodelan dengan teknik Structural equation modeling (SEM). Software yang digunakan di dalam proses analisis data adalah SPSS dan Amos.

\subsection{Teknik Analisis}

Teknik analisis data dalam penelitian ini menggunakan Structural Equation Model (SEM) dengan program AMOS.21. Data yang telah dikumpulkan berdasarkan kuesioner kemudian dilakukan analisis untuk mengolah data tersebut agar hasilnya dapat dianalisis sesuai dengan kebutuhan dan sesuai dengan permasalahan yang telah ditentukan. Alat analisis yang dimaksud adalah Structural Equation Modeling (SEM). Model persamaan struktural (Structural Equation Modeling) adalah generasi kedua teknik analisis multivariate yang memungkinkan peneliti 
untuk menguji hubungan antara variabel yang kompleks baik recursive maupun non-recursive untuk memperoleh gambaran menyeluruh mengenai keseluruhan model (Ghozali, 2005).

Structural Equation Modeling (SEM) ini digunakan untuk :

a. menguji kesalahan pengukuran (measurement error) sebagai bagian yang tidak terpisahkan dari SEM.

b. Melakukan analisis faktor bersamaan dengan pengujian hipotesis.

Structural Equation Modeling (SEM) dilakukan dengan bantuan program AMOS.

\section{Analisis dan Pembahasan}

\subsection{Analisis Deskriptif}

\subsubsection{Analisis Karakteristik Responden}

\section{a. Jenis kelamin responden}

Berdasarkan jenis kelamin responden, terdiri atas dua kelompok, yaitu kelompok pria dan wanita. Hasil analisis data ini diperoleh persentase responden berdasarkan jenis kelamin seperti ditunjukkan pada tabel berikut:

Tabel 2 Jenis Kelamin Responden

\begin{tabular}{lllrrr}
\hline & & \multicolumn{2}{c}{ Responden } & \\
\cline { 3 - 5 } Jenis Kelamin & Laki-laki & Count & Nasabah & Non Nasabah & Total \\
\cline { 3 - 5 } & & \% of Total & 39 & 42 & 91 \\
& Perempuan & Count & 24 & $28.8 \%$ & $62.3 \%$ \\
\hline & & \% of Total & $16.4 \%$ & 31 & 55 \\
& & Count & 73 & $21.2 \%$ & $37.7 \%$ \\
\hline Total & \% of Total & $50.0 \%$ & 73 & 146 \\
& & & $50.0 \%$ & $100.0 \%$ \\
\hline
\end{tabular}

Berdasarkan Tabel 2 dapat diketahui bahwa 62 persen responden berjenis kelamin pria dan 38 persen responden berjenis kelamin wanita. Begitu juga dengan responden nasabah mayoritas adalah laki-laki $(33,6 \%)$ dan Non nasabah juga laki-laki $(28,8 \%)$. Ditinjau dari besarnya persentase menunjukkan bahwa responden yang berminat untuk menjadi nasabah di Bank Syariah mayoritas adalah responden dengan laki-laki.

\section{b. Usia}

Usia seseorang merupakan faktor yang dapat menentukan penilaian nasabah karena pengetahuan, pandangan, pengalaman dan keyakinan sehingga akan mempengaruhi persepsi dalam menentukan obyek. Tabel 3 menunjukkan usia responden. Dari data tersebut menunjukkan bahwa responden yang memilih bertransaksi pada Bank Syariah mayoritas berusia lebih 31-40 tahun, yaitu sebesar 38\%. Sedangkan distribusi usia yang lain yaitu usia antara 41-50 tahun sebesar 31\%, antara 20 - 30 tahun sebesar $21 \%$ dan lebih dari 50 tahun sebesar $10 \%$. Ditinjau dari perbandingan antara nasabah dengan non nasabah menunjukkan bahwa nasabah Bank Syariah mayoritas berusia 31 - 40 tahun (20,5\%), sama dengan responden non nasabah yang mayoritas berusia $31-40$ tahun $(17,8 \%)$. Kenyataan menunjukkan bahwa mayoritas nasabah dan calon nasabah Bank Syariah adalah berusia dewasa atau produktif. 
Tabel 3 Usia Responden

\begin{tabular}{|c|c|c|c|c|c|}
\hline & & & \multicolumn{2}{|c|}{ Responden } & \multirow[b]{2}{*}{ Total } \\
\hline & & & Nasabah & Non Nasabah & \\
\hline \multirow[t]{8}{*}{ Usia } & $20-30$ tahun & Count & 12 & 19 & 31 \\
\hline & & $\%$ of Total & $8.2 \%$ & $13.0 \%$ & $21.2 \%$ \\
\hline & $31-40$ tahun & Count & 30 & 26 & 56 \\
\hline & & $\%$ of Total & $20.5 \%$ & $17.8 \%$ & $38.4 \%$ \\
\hline & $41-50$ tahun & Count & 21 & 24 & 45 \\
\hline & & $\%$ of Total & $14.4 \%$ & $16.4 \%$ & $30.8 \%$ \\
\hline & $>40$ tahun & Count & 10 & 4 & 14 \\
\hline & & $\%$ of Total & $6.8 \%$ & $2.7 \%$ & $9.6 \%$ \\
\hline \multirow[t]{2}{*}{ Total } & & Count & 73 & 73 & 146 \\
\hline & & $\%$ of Total & $50.0 \%$ & $50.0 \%$ & $100.0 \%$ \\
\hline
\end{tabular}

\section{c. Tingkat pendidikan}

Hasil angket yang telah disebarkan diperoleh hasil seperti terlihat pada Tabel 4.

Tabel 4 Pendidikan Responden

\begin{tabular}{|c|c|c|c|c|c|}
\hline & & & \multicolumn{2}{|c|}{ Responden } & \multirow[b]{2}{*}{ Total } \\
\hline & & & Nasabah & Non Nasabah & \\
\hline \multirow{10}{*}{ Pendidikan } & \multirow[b]{2}{*}{ SMA } & Count & 24 & 18 & 42 \\
\hline & & $\%$ of Total & $16.4 \%$ & $12.3 \%$ & $28.8 \%$ \\
\hline & \multirow[b]{2}{*}{ Diploma } & Count & 4 & 15 & 19 \\
\hline & & $\%$ of Total & $2.7 \%$ & $10.3 \%$ & $13.0 \%$ \\
\hline & \multirow[b]{2}{*}{ Sarjana S1 } & Count & 32 & 31 & 63 \\
\hline & & $\%$ of Total & $21.9 \%$ & $21.2 \%$ & $43.2 \%$ \\
\hline & \multirow[b]{2}{*}{ Sarjana S2 } & Count & 10 & 6 & 16 \\
\hline & & $\%$ of Total & $6.8 \%$ & $4.1 \%$ & $11.0 \%$ \\
\hline & \multirow[b]{2}{*}{ Lainnya } & Count & 3 & 3 & 6 \\
\hline & & $\%$ of Total & $2.1 \%$ & $2.1 \%$ & $4.1 \%$ \\
\hline \multirow[b]{2}{*}{ Total } & & Count & 73 & 73 & 146 \\
\hline & & $\%$ of Total & $50.0 \%$ & $50.0 \%$ & $100.0 \%$ \\
\hline
\end{tabular}

Dari data di atas menunjukkan bahwa karakteristik responden berdasarkan pendidikan adalah sama antara nasabah dan non nasabah yang mayoritas juga berpendidikan Sarjan S1 yaitu sebesar 21,9\% untuk nasabah Bank Syariah dan 21,2\% untuk non nasabah. Kenyataan menunjukkan bahwa mayoritas nasabah dan calon nasabah Bank Syariah telah memiliki pendidikan yang tinggi, sehingga memiliki tingkat pengetahuan dan pengalaman yang cukup dalam memilih menggunakan jasa perbankan, karena tingkat pendidikan seseorang menunjukkan tingkat intelegensi dan pengalaman yang dimiliki oleh nasabah.

\section{d. Jenis pekerjaan}

Hasil angket yang telah disebarkan diperoleh hasil seperti terlihat pada Tabel 5. 
Tabel 5 Pekerjaan Responden

\begin{tabular}{|c|c|c|c|c|c|}
\hline & & & \multicolumn{2}{|c|}{ Responden } & \multirow[b]{2}{*}{ Total } \\
\hline & & & Nasabah & Non Nasabah & \\
\hline \multirow[t]{10}{*}{ Pekerjaan } & Mahasiswa & Count & 1 & 5 & 6 \\
\hline & & $\%$ of Total & $.7 \%$ & $3.4 \%$ & $4.1 \%$ \\
\hline & Karyawan Swasta & Count & 27 & 26 & 53 \\
\hline & & $\%$ of Total & $18.5 \%$ & $17.8 \%$ & $36.3 \%$ \\
\hline & Wiraswasta & Count & 35 & 35 & 70 \\
\hline & & $\%$ of Total & $24.0 \%$ & $24.0 \%$ & $47.9 \%$ \\
\hline & PNS & Count & 3 & 3 & 6 \\
\hline & & $\%$ of Total & $2.1 \%$ & $2.1 \%$ & $4.1 \%$ \\
\hline & Lainnya & Count & 7 & 4 & 11 \\
\hline & & $\%$ of Total & $4.8 \%$ & $2.7 \%$ & $7.5 \%$ \\
\hline \multirow[t]{2}{*}{ Total } & & Count & 73 & 73 & 146 \\
\hline & & $\%$ of Total & $50.0 \%$ & $50.0 \%$ & $100.0 \%$ \\
\hline
\end{tabular}

Dari Tabel 5 di atas menunjukan bahwa menunjukan bahwa Hasil yang sama jika dibandingkan profil nasabah Bank Syariah dengan non nasabah berdasarkan pekerjaan, mayoritas adalah wiraswasta yaitu masing-masing sebesar $24 \%$. Kenyataan ini berarti pekerjaan responden yang berminat menggunakan jasa Bank Syariah adalah wiraswasta/pengusaha. Hal ini disebabkan karena responden yang memiliki pekerjaan sebagai wiraswasta / pengusaha adalah seorang pekerja atau pebisnis, sehingga membutuhkan jasa perbankan baik untuk keperluan usaha maupun sebagai tempat mendapatkan dana pinjaman.

\section{e. Penghasilan responden}

Hasil analisis data ini diperoleh frekuensi data seperti ditunjukkan pada tabel berikut.

Tabel 6 Penghasilan Responden

\begin{tabular}{|c|c|c|c|c|c|}
\hline & & & \multicolumn{2}{|c|}{ Responden } & \multirow[b]{2}{*}{ Total } \\
\hline & & & Nasabah & Non Nasabah & \\
\hline \multirow[t]{12}{*}{ Penghasilan } & $<$ Rp. 5 juta & Count & 2 & 15 & 17 \\
\hline & & $\%$ of Total & $1.4 \%$ & $10.3 \%$ & $11.6 \%$ \\
\hline & Rp. 6 - 10 juta & Count & 23 & 28 & 51 \\
\hline & & $\%$ of Total & $15.8 \%$ & $19.2 \%$ & $34.9 \%$ \\
\hline & Rp. 11 - 20 juta & Count & 23 & 18 & 41 \\
\hline & & $\%$ of Total & $15.8 \%$ & $12.3 \%$ & $28.1 \%$ \\
\hline & Rp.20 - 50 juta & Count & 14 & 7 & 21 \\
\hline & & $\%$ of Total & $9.6 \%$ & $4.8 \%$ & $14.4 \%$ \\
\hline & Rp.50 - 100 juta & Count & 4 & 2 & 6 \\
\hline & & $\%$ of Total & $2.7 \%$ & $1.4 \%$ & $4.1 \%$ \\
\hline & $>$ Rp. 100 juta & Count & 7 & 3 & 10 \\
\hline & & $\%$ of Total & $4.8 \%$ & $2.1 \%$ & $6.8 \%$ \\
\hline \multirow[t]{2}{*}{ Total } & & Count & 73 & 73 & 146 \\
\hline & & $\%$ of Total & $50.0 \%$ & $50.0 \%$ & $100.0 \%$ \\
\hline
\end{tabular}

Dari tabel 6 menunjukkan bahwa mayoritas nasabah dan calon nasabah Bank Syariah adalah berpenghasilan menengah keatas, sehingga cukup memiliki dana untuk menyimpan dananya di 
Bank Syariah, tetapi pendapatan nasabah Bank Syariah lebih tinggi dibandingkan pendapatan non nasabah

\section{f. Hal yang menarik menjadi nasabah Bank Syariah}

Alasan menjadi nasabah Bank Syariah diberikan oleh responden yang telah menjadi nasabah Bank Syariah, dan secara garis besar beberapa alasan utama mereka adalah sebagai berikut :

\begin{tabular}{lcc}
\hline \multicolumn{1}{c}{ Alasan menjadi nasabah } & Jumlah & Persentase \\
\hline Bagi hasil yang besar & 11 & $15.1 \%$ \\
\hline Lokasi & 9 & $12.3 \%$ \\
\hline Pelayanan dan kemudahan & 9 & $12.3 \%$ \\
\hline Promosi dan iklan & 12 & $16.4 \%$ \\
\hline Produk dan bebas riba & 13 & $17.8 \%$ \\
\hline Biaya Rendah & 6 & $8.2 \%$ \\
\hline Alasan lain & 13 & $17.8 \%$ \\
\hline Total & 73 & $100 \%$ \\
\hline
\end{tabular}

Hal yang menarik dalam temuan ini adalah riba juga menjadi alasan bagi Etnis Thionghoa Non Muslim untuk menjadi nasabah Bank Syariah. Hal ini ada beberapa konsep dalam setiap agama jika dikaji lebih jauh, bahwa setiap agama pada prinsipnya juga melarang riba.

\section{g. Hal yang harus diperbaiki Bank Syariah}

Menurut pendapat nasabah etnis Thionghoa, berdasarkan pengalamanya menjadi nasabah Bank Syariah, memberikan pendapat tentang hal-hal apa saja yang harus diperbaiki oleh Bank Syariah diantaranya :

\section{Tabel 8 Hal yang harus diperbaiki Bank Syariah}

\begin{tabular}{lcc}
\hline \multicolumn{1}{c}{ Hal yang diperbaiki Bank Syariah } & Jumlah responden & Persentase \\
\hline Hadiah dan Undian & 16 & $21.9 \%$ \\
\hline Fasilitas & 6 & $8.2 \%$ \\
\hline Sosialisasi dan promosi & 11 & $15.1 \%$ \\
\hline Pelayanan & 18 & $24.7 \%$ \\
\hline Variasi produk & 9 & $12.3 \%$ \\
\hline SDM & 5 & $6.8 \%$ \\
\hline Lainnya & 8 & $11.0 \%$ \\
\hline Total & 73 & $100.0 \%$ \\
\hline
\end{tabular}

Dari data diatas menunjukkan bahwa pelayanan dan pemberian hadiah merupakan dasar dari pelayanan bank yang harus ditingkatkan untuk menarik nasabah yang sebesar-besarnya. Namun hal yang menarik adalah karena kurang sosialisasi dan promosi dari Bank Syariah, sehingga konsep syariah belum banyak diketahui dan diahami terutama di kalangan etnis Thionghoa yang beragama non muslim. 


\subsection{Analisis Kuantitatif}

Analisis data dalam penelitian ini menggunakan teknik analisis Structural Equation Model (SEM). SEM dapat menguji beberapa variabel dependen sekaligus dengan beberapa variabel independen (Augusty Ferdinand, 2006). SEM adalah alat statistik yang merupakan gabungan dari dua model statistik yang terpisah yaitu analisis faktor dan analisis regresi. Model penelitian melalui SEM memungkinkan peneliti untuk menjawab pertanyaan penelitian yang bersifat regresi maupun dimensional (mengukur dimensi apa saja dari sebuah konsep). Untuk penelitian ini menggunakan program SEM AMOS 21 yang dapat mengolah model penelitian yang berdimensi dan berjenjang.

\subsubsection{Uji Validitas dan Reliabilitas dengan Program AMOS 16.0}

Sebelum menguji hipotesis, terlebih dahulu dilakukan uji validitas dan reliabilitas data yang akan dianalisa. Untuk menaksir validasi item pertanyaan, penelitian ini menggunakan Confirmatory Factor Analysis (CFA), dan diolahmenggunakan program AMOS 21. Data dinyatakan valid jika standardized loading factor $(\lambda)$ untuk masing-masing indikator variabel minimum 0,50 (Ghozali, 2011). Sedangkan pengujian reliabilitas digunakan Composite Reliability. Jika nilai Composite Reliability > 0,7 maka instrumen penelitian dapat dinyatakan reliabel.

Tabel 9 Hasil Uji Validitas dan Reliabilitas

\begin{tabular}{|c|c|c|c|c|c|c|}
\hline Indikator & $\lambda \mathrm{i}$ & $\varepsilon \mathrm{i}$ & $\sum \lambda \mathrm{i}$ & $\varepsilon \mathrm{i}$ & $\begin{array}{l}\text { Composite } \\
\text { Reliability }\end{array}$ & Keterangan \\
\hline Sosial & & & 1.493 & 0.683 & 0.765 & Reliabel \\
\hline Kerabat / Keluarga & 0.755 & 0.383 & & & & Valid \\
\hline Media Masa & 0.738 & 0.300 & & & & Valid \\
\hline Individu & & & 1.469 & 0.438 & 0.831 & Reliabel \\
\hline Pengetahuan & 0.746 & 0.221 & & & & Valid \\
\hline Sesuai Syariah & 0.723 & 0.217 & & & & Valid \\
\hline Kultur & & & 1.722 & 0.422 & 0.875 & Reliabel \\
\hline Berhemat & 0.792 & 0.307 & & & & Valid \\
\hline Nilai Kejujuran & 0.930 & 0.115 & & & & Valid \\
\hline Persepsi Atribut & & & 4.931 & 1.597 & 0.938 & Reliabel \\
\hline Marketing & 0.893 & 0.065 & & & & Valid \\
\hline Produk feature & 0.646 & 0.267 & & & & Valid \\
\hline Reputation Image & 0.531 & 0.289 & & & & Valid \\
\hline Quality Sevice & 0.831 & 0.123 & & & & Valid \\
\hline Higher Return & 0.501 & 0.309 & & & & Valid \\
\hline Lokasi & 0.766 & 0.311 & & & & Valid \\
\hline Teknologi & 0.763 & 0.233 & & & & Valid \\
\hline Awareness & & & 1.854 & 0.199 & 0.945 & Reliabel \\
\hline Menghindari bunga & 0.911 & 0.127 & & & & Valid \\
\hline Hukum Islam & 0.943 & 0.072 & & & & Valid \\
\hline Desire & & & 1.719 & 0.361 & 0.891 & Reliabel \\
\hline Merekomendasikan & 0.786 & 0.256 & & & & Valid \\
\hline
\end{tabular}




\begin{tabular}{ccccccc}
\hline Indikator & $\lambda \mathrm{i}$ & $\varepsilon \mathrm{i}$ & $\Sigma \lambda \mathrm{i}$ & $\varepsilon \mathrm{i}$ & $\begin{array}{c}\text { Composite } \\
\text { Reliability }\end{array}$ & Keterangan \\
\hline Terus menggunakan & 0.933 & 0.105 & & & & Valid \\
\hline $\begin{array}{c}\text { Interest } \\
\begin{array}{c}\text { Tertarik menjadi } \\
\text { nasabah }\end{array}\end{array}$ & 0.936 & 0.118 & & & 0.900 & Reliabel \\
$\begin{array}{c}\text { Ingin menggali } \\
\text { informasi }\end{array}$ & 0.795 & 0.214 & & & & Valid \\
\hline
\end{tabular}

Berdasarkan tabel 4.12 di atas, dapat diketahui bahwa seluruh item pertanyaan memiliki loading (Confirmatory Factor Analysis) yang nilainya diatas 0,5 sehingga seluruh butir pertanyaan dapat dinyatakan valid. Sedangkan hasil uji reliabilitas dapat dinyatakan reliable, karena memiliki nilai Composite Reliability yang disyaratkan yaitu di atas nilai kritis $(>0,7)$.

\subsubsection{Uji Kebaikan Model (Goodness of Fit)}

Untuk mengetahui kriteria model yang baik (Goodness of Fit) digunakan: Absolut Fit Measured (pengukuran indeks mutlak), Incremental Fit Measured (Pengukuran tambahan indeks) dan Parsimonious Fit Measured (Pengukuran kesederhanaan indeks). Uji kebaikan model ini menggunakan software Amos versi 21.0. Berikut ini goodness of fit index yang dihasilkan setelah pengujian :

Tabel 10 Goodness of Fit Index

\begin{tabular}{lccc}
\hline \multicolumn{1}{c}{ Goodness of Fit Index } & Cut Off Value & Hasil & Kriteria \\
\hline Likelihood Chi Square & 133,25 & 206,301 & Marginal \\
Probability & $\geq 0,05$ & 0,000 & Marginal \\
CMIN/DF & $\leq 3$ & 1,910 & Baik \\
RMSEA & $\leq 0,08$ & 0,079 & Baik \\
GFI & $\geq 0,9$ & 0,880 & Marginal \\
AGFI & $\geq 0,9$ & 0,789 & Marginal \\
TLI & $\geq 0,9$ & 0,910 & Baik \\
NFI & $\geq 0,9$ & 0,891 & Marginal \\
CFI & $\geq 0.9$ & 0,943 & Baik \\
\hline
\end{tabular}

Hasil analisis pengolahan data terlihat bahwa semua konstruk yang digunakan untuk membentuk sebuah model penelitian, pada proses analisis full model SEM memenuhi kriteria goodness of fit yang telah ditetapkan. Ukuran goodness of fit yang menunjukkan kondisi yang fit hal ini disebabkan oleh angka TLI $(0,910>0,9)$; CFI $(0,943>0,9)$; CMIN/DF $(1,910<3)$; RMSEA $(0,079<0,8)$. Sedangkan Chi-square sebesar 206,301 yang lebih besar dari cut-off value yang ditetapkan yaitu chi square tabel dengan $\mathrm{DF}=108$ sebesar 133,25 dengan nilai probability 0,000 atau dibawah 0,05 , nilai ini menunjukkan tidak adanya perbedaan antara matriks kovarian sample dengan matriks kovarian populasi yang diestimasi. Selain itu GFI $(0,880<0,9)$, AGFI $(0,789<0,9)$ dan NFI $(0,891<0,9)$ termasuk kriteria goodness of fit yang marginal. Tapi, merujuk pada prinsip parsimony dan rule of tumb, maka jika terdapat satu atau dua kriteria goodness of fit yang telah memenuhi, maka model dikatakan baik (Rinaldo,2009).

\subsubsection{Hasil Pengujian Hipotesis}

Seperti dijelaskan pada bab sebelumnya, hipotesis yang dirumuskan dalam penelitian ini terdiri dari 4 hipotesis. Untuk mengetahui apakah hipotesis didukung oleh data atau tidak, maka nilai probabilitas dari Critical Ratio (C.R) dibandingkan dengan $\alpha=5 \%$. Apabila Standardized 
Koefisien parameter memiliki nilai probabilitas dari Critical Ratio (C.R) kurang dari $\alpha=5 \%$, maka dapat disimpulkan bahwa hipotesis penelitian didukung oleh data (terbukti secara signifikan). Hasil pengujian terhadap model penelitian dapat digambarkan sebagai berikut:

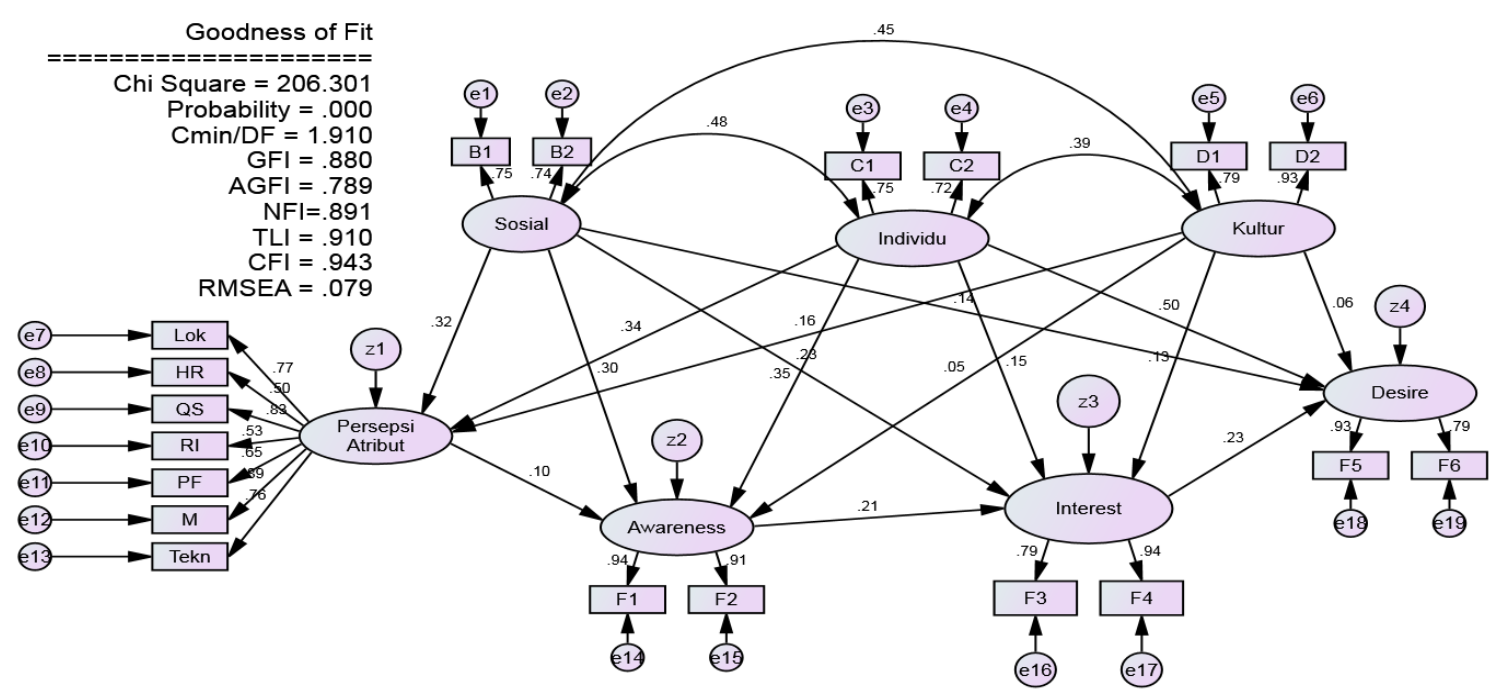

Gambar 6 Hasil Model Penelitian Keseluruhan Sampel

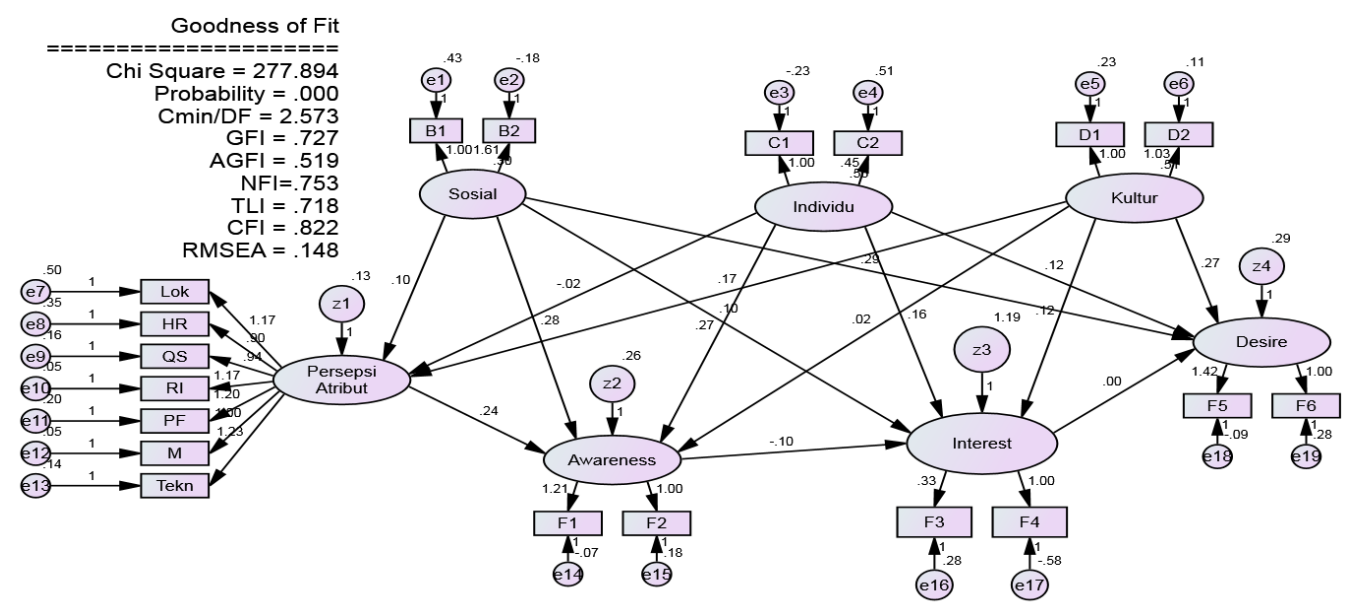

Gambar 7 Hasil Model Penelitian Nasabah 


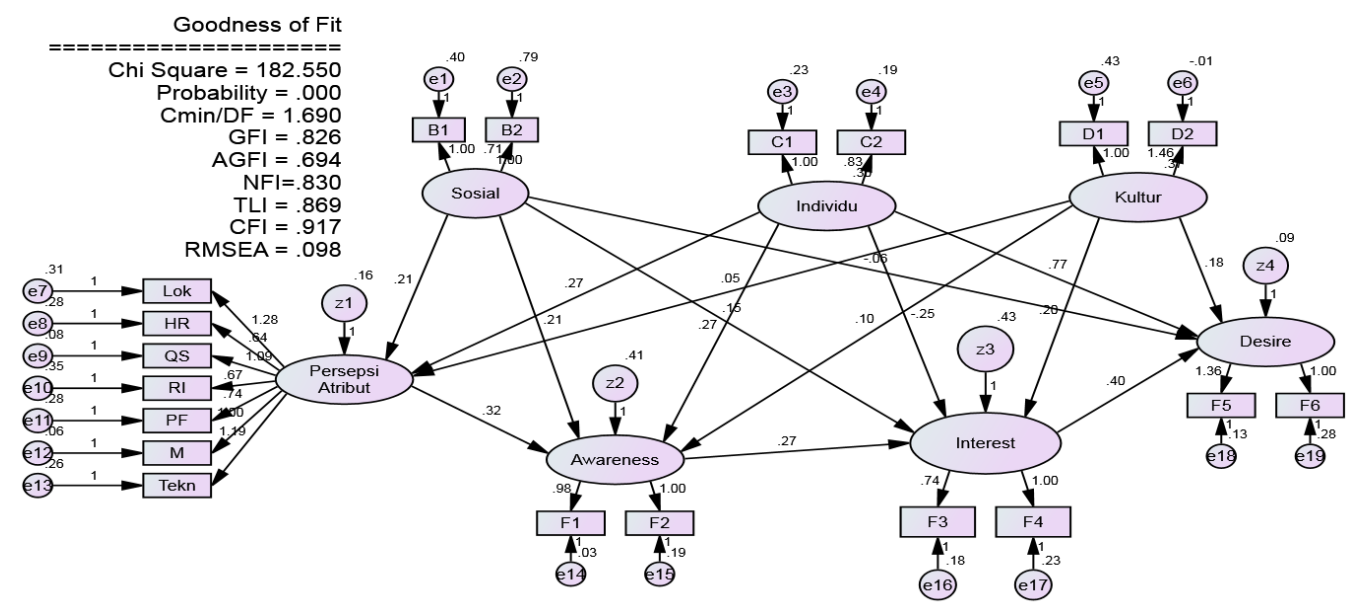

Gambar 8 Hasil Model Penelitian Non Nasabah

Berdasarkan analisis statistik dengan menggunakan program AMOS versi 21, diperoleh hasil uji hipotesis yang merupakan uji hubungan kausalitas dari masing-masing variabel penelitian sebagaimana disajikan pada tabel berikut ini.

Tabel 11 Hasil Estimasi Dengan Model AMOS

\begin{tabular}{llllllll}
\hline & \multicolumn{2}{c}{ Full Sample } & \multicolumn{2}{c}{ Nasabah } & \multicolumn{2}{c}{ Non Nasabah } & Keterangan \\
\hline & Koef & $p$-value & Koef & $p$-value & Koef & $p$-value & \\
\hline Individu & 0.343 & 0.001 & -0.039 & 0.672 & 0.284 & 0.032 & H1 didukung \\
$\rightarrow$ Persepsi_Atribut & 0.155 & 0.099 & 0.318 & 0.018 & 0.065 & 0.556 & \\
Kultur $\rightarrow$ Persepsi_Atribut & 0.324 & 0.004 & 0.135 & 0.195 & 0.417 & 0.007 & \\
Sosial $\rightarrow$ Persepsi_Atribut & 0.103 & 0.326 & 0.156 & 0.128 & 0.213 & 0.107 & H2 didukung \\
\hline Persepsi Atribut & 0.350 & 0.000 & 0.346 & 0.028 & 0.190 & 0.066 & \\
$\rightarrow$ Awareness & 0.053 & 0.518 & 0.029 & 0.782 & 0.081 & 0.371 & \\
Individu $\rightarrow$ Awareness & 0.302 & 0.009 & 0.263 & 0.024 & 0.267 & 0.053 & \\
\hline Kultur $\rightarrow$ Awareness & 0.227 & 0.041 & 0.049 & 0.483 & 0.205 & 0.220 & H3 didukung \\
Sosial $\rightarrow$ Awareness & 0.153 & 0.194 & 0.106 & 0.155 & -0.187 & 0.234 & \\
\hline Sosial $\rightarrow$ Interest & 0.128 & 0.278 & 0.075 & 0.423 & 0.166 & 0.371 & \\
Individu $\rightarrow$ Interest & 0.206 & 0.039 & -0.054 & 0.438 & 0.280 & 0.064 & \\
Kultur $\rightarrow$ Interest & 0.062 & 0.521 & 0.313 & 0.016 & 0.182 & 0.171 & H4 didukung \\
Awareness $\rightarrow$ Interest & 0.502 & 0.000 & 0.150 & 0.147 & 0.682 & 0.000 & \\
\hline Kultur $\rightarrow$ Desire & 0.138 & 0.320 & 0.256 & 0.018 & -0.094 & 0.640 & \\
Individu $\rightarrow$ Desire & 0.225 & 0.026 & -0.007 & 0.907 & 0.479 & 0.001 & \\
Sosial $\rightarrow$ Desire & & & & & &
\end{tabular}

\section{Kesimpulan dan Saran}

\subsection{Kesimpulan}

Berdasarkan hasil analisis data maka dapat disimpulkan: 
1. Faktor faktor-faktor yang mempengaruhi etnis Tionghoa Non Muslim menjadi nasabah Bank Syariah terdiri dari faktor individu, faktor sosial dan faktor budaya.

2. Faktor sosial berpengaruh signifikan terhadap persepsi atribut, awareness dan interest tetapi tidak berpengaruh signifikan terhadap desire. Hal ini berarti faktor sosial yang mendukung akan meningkatkan persepsi terhadap atribut Bank Syariah, kesadaran untuk menjadi nasabah Bank Syariah dan memiliki ketertarikan tetapi belum mampu meningkatkan minat nasabah.

3. faktor individu berpengaruh signifikan terhadap persepsi atribut, awareness dan desire tetapi tidak berpengaruh signifikan terhadap interest. Hal ini berarti kondisi individu nasabah dan calon nasabah akan berpengaruh terhadap persepsinya pada atribut Bank Syariah, kesadaran dan minat menjadi nasabah.

4. Faktor budaya tidak berpengaruh signifikan terhadap persepsi atribut, awareness, interest dan desire. Hal ini menunjukkan bahwa budaya seseorang tidak mempengaruhi keputusan untuk menajdi nasabah Bank Syariah karena atribut produk, kesadaran, ketertarikan dan minat.

\subsection{Saran}

Berdasarkan hasil kesimpulan dapat diberikan saran yang bermanfaat bagi :

1. Manajemen Bank Syariah hendaknya meningkatan aspek return yg lebih kompetitif dibanding bank konvensional dengan menerapkan nisbah yang tepat dan adil, baik dari segi pendanaan maupun pembiayaan.

2. Manajemen Bank Syariah yg selama ini identik dengan pangsa pasar muslim kelas midlelow, hendaknya dapat memanfaatkan segmentasi pasar (etnis Tionghoa) yg sangat potensial ini. Dengan sosialisasi dan promosi yang tepat. Contoh dapat menggandeng Aktor, Tokoh Agama, Artis, Atlit, dan Public Figur lainnya (dari kalangan Tionghoa). Sehingga mampu memotivasi dan meyakinkan nasabah dan calon nasabah dari etnis Tionghoa ini.

3. Untuk peneliti selanjutnya dapat melakukan penelitian yang sama dengan teknik yang berbeda, misalnya menyebar kuesioner melalui mailis, sehingga dapat menjaring responden sebanyak-banyaknya dan akan efektif dibandingkan dengan metode konvensional.

\section{Daftar Pustaka}

Al-Quran.

Abdulrasheed A. Influence Of Personality Variables On People's Attitude Towards Usage Of Banks In Ilorin Metropolis [Research Field:Department Of Accounting And Finance]. Ilorin (ID): UniversityOf Ilorin.

Adawiyah RW. 2010. Pertimbangan, Pengetahuan, dan Sikap Konsumen Individu Terhadap Bank Syariah. Jurnal Ekonomi Pembangunan. Vol. 11 No.2.

Assael, H. 1992. Consumer Behavior \& Marketing Action, USA: PWS-KENT Publishing Company.

Amin Muslim, Isa Zaidi. 2008. An Examination Of The Relationship Between Service Quality Perception And Customer Satisfactio. International Journal Of Islamic And Middle Eastern Finance And Management. Vol 1.No. 3, 2008 pp. 191-209.

Arifin Atwal, Khotimah Husnul. 2014. Pengaruh Produk, Pelayanan, Promosi, dan Lokasi terhadap Keputusan Masyarakat memilih Bank Syariah di Surakarta. Seninar Nasional dan Call for Paper. ISBN: 978-602-70429-2-6.

Armstrong J Scott. 1991. Prediction Of Consumer Behavior By Experts And Novices. Journal Of Consumer Research. Vo. 18. 251-256. 
Awan Hayat M, Bukhari KS. 2011. Customer's Criteria for Selecting an Islamic Bank: Evidence From Pakistan. Journal of Islamic Marketing. Vol 2 No. 1, 2011.

Bank Indonesia. 2002. Cetak Biru Pengembangan Perbankan Syariah Indonesia.Jakarta: Bank Indonesia.

Biro Perbankan Syariah Bank Indonesia. 2013. Statistik Perbankan Syariah Maret 2013. Jakarta: Bank Indonesia.

-----. 2013. Statistik Perbankan Syariah Maret 2003. Jakarta: Bank Indonesia.

----. 2013. Laporan Triwulanan Perbankan Syariah-Triwulan I/2013. Jakarta: Bank Indonesia.

Dusuki AW, Abdullah NI. 2007. Why Do Malaysian Customers Patronise Islamic Banks?. International JournalOf Bank Marketing. Vol. 25 No. 3, 2007.

Dwiastuti R, Sinta A, Isaskar R. 2012. Ilmu Perilaku Konsumen. Cetakan Pertama. Malang (ID): UB Press.

Haron Sudin, Ahmad Norafifah, Planisek Sandra L. 1994. Bank Patronage Factors of Muslim and Non-Muslim Customers. International Journal Of BankMarketing. Vol.12 No.1, 1994, pp. 32-40

Erol C, El-Bdour R. 2007. Attitudes, Behaviour and Petronage Factors Of Bank Customers Towards Islamic Banks [Emerald BackFiles 2007]. Jordan (ID): Yarmouk University.

Engel, J.F.,Blackwell, R.D. dan Miniard, P.W. 1995. Perilaku Konsumen Jilid 2 Edisi Keenam.Jakarta (ID): Binarupa Aksara.

Feist, Jess, and Feist, J., Gregory. 2008. Theories of Personality. Yogyakarta: Pustaka Pelajar.

Hafiduddin D, Tanjung H. 2003. Manajemen Syariah. Cetakan Pertama. Jakarta (ID): Gema Insani

Hidajat. 1984. Masyarakat dan Kebudayaan Cina Indonesia. Bandung: TARSITO.

Hidayat SE, Al-Bawari NK. 2011. Non-Muslims' Perceptions Toward Islamic Banking Services In Saudi Arabia. [Research Field : Islamic Banking And Finance]. Bahrain (ID): University College Of Bahrain.

Hejase Hussin. 2012. Marketing Mix: An Exploratory Research In Syria From An Islamic Perspective. AmericanJournal Of Scientific Research. pp.33-52.

Haron, S., Ahmad, Norafifah., and Planisek, Sandra, L. 1994.Bank PatronageFactors of Muslim and Non-MuslimCustomers, International Journal of BankMarketing. Volume: 12 Issue: 1 Page: $32-40$.

Husodo, Siswono Yudo. 1985. Warga Baru (Kasus Cina Di Indonesia). Jakarta: Lembaga Penerbitan Yayasan Padamu Negeri.

http://arryrahmawan.net/teknik-pemasaran-dengan-7p-marketing-mix/

http://historyrendhy.blogspot.com/2012/06/dominasi-etnis-cina-dalam-kegiatan.html

http://id.wikipedia.org/wiki/Tionghoa-Indonesia

http://iccsg.wordpress.com/2006/01/23/perilaku-ekonimi-etnis-cina-di-Indonesia-sejak-tahun1930-an-fr-wulandari/

Iska S. 2012. Sistem Perbankan Syariah di Indonesia Dalam Perspektif Fikih Ekonomi. Cetakan Pertama. Yogyakarta (ID): Fajar Media Press.

Kanuk, Leslie, Lazar, and Schiffman, Leon, G. 2007. Consumer Behavior, New Jersey: Prentice-Hall Inc.

Khan MSN, Hassan MK, Shaid AI. 2007. Banking Behavior Of Islamic Bank Customers In Bangladesh. Journal Of Islamic Economic, Banking and Finance.

K Yulianto F, Yuniarinto A, Surachman. 2010. Analisis Pengaruh Faktor Bauran Pemasaran Terhadap Pertimbangan Nasabah Dalam Memilih Bank Syariah Di Kota Medan. Wacana. Vol. 13 No. 4.

Mackie.1991. Peran Ekonomi dan Identitas Etnis Cina Indonesia dan Muangthai. Jakarta: Pustaka Utama Grafika.

Markhamah, 2000.Etnik Cina: Kajian Linguistik Kultural. Surakarta: Muhammadiyah University Press.

Maski G. 2010. Analisis Keputusan Nasabah Menabung. Journal Of Indonesian Applied Economics. Vol. 4 No. 1. 
Naisbitt, J. (1997). Megatrends Asia. New York: Touchstone Rockefeller Center.

Mutasowifin A. 2003. Menggagas Strategi Pengembangan Perbankan Syariah di Pasar Non Muslim. Jurnal Universitas Paramadina. Vol. 3 No.1.

Rangkuti F. 2005. Marketing Analysis Made Easy.Jakarta (ID) : PT Gramedia Pustaka Utama.

R Aritonang LR. 2007. Riset Pemasaran Teori \& Praktik. Cetakan Pertama. Jakarta(ID): Ghalia Indonesia.

Sutanto H, Umam K. 2013. Manajemen Pemasaran Bank Syariah.Cetakan Pertama. Bandung(ID): Pustaka Setia.

Sumarwan U. 2013.Pemasaran Strategik: Perspektif Value-Based Marketing \& Pengukuran Kinerja. Cetakan ke-3. Bogor (ID): IPB Press.

Sumarwan U. 2011. Perilaku Konsumen: Teori dan Penerapannya dalam Pemasaran. Edisi ke2.Cetakan ke-3. Bogor (ID): Ghalia Indonesia.

Tarmizi E.2012. Harta Haram Mualamah Kontemporer. Catakan ke-3. Bogor (ID): Berkat Mulia Insani.

Wibowo M. 2010. Perilaku Konsumen Pengaruhnya Terhadap Keputusan Menjadi Nasabah Pada Kopwan Syariah. Jurnal Dinamika Manajemen. Vol. 1 No. 1.

Widyahartono, Bob. 1988. Kongsi dan Spekulasi Jaringan Kerja Bisnis Cina. Jakarta: Pustaka Utama Grafiti.

www.matahaticorp.com/kini-saatnya-etnis-cina-berkuasa-penuh-di-ri/

Zein, Abdul Baqir.2000. Etnis Cina Dalam Potret Pembauran Indonesia. Jakarta: Prestasi Insan Indonesia. 